\title{
A novel method of furan determination in beer using gas chromatography with a flame ionization detector
}

\author{
Jana Olšovská, Tomáš Horák*, Karel Štěrba \\ Research Institute of Brewing and Malting \\ Lípová 511/15, 12000 Prague 2 \\ Czech Republic
}

*corresponding e-mail: horak@beerresearch.cz

\begin{abstract}
Furan is considered to have a potential carcinogenic effect on human health. Its presence was found in a number of foods including beer. Thus, it is necessary to have a fast and routine method for its determination. This study describes a procedure meeting these requirements using the head-space technique associated with gas chromatography. A capillary column with the length of $60 \mathrm{~m}$, inner diameter of $0.32 \mathrm{~mm}$ and the film thickness of $0.25 \mu \mathrm{m}$ was used for the determination of furan. A flame-ionization detector (FID) was used for the detection. The characteristics of the procedure are presented.
\end{abstract}

Keywords: beer, furan, head-space, gas chromatography

\section{Introduction}

Furan is a colorless, low boiling heterocyclic compound. It definitely is a carcinogenic substance to rats and mice. It is also classified as a possible carcinogen when considering human health (International Agency for Research on Cancer, 1995; Crews and Castle, 2007).

Furan was found in a large number of different foods, especially those that were thermally treated in a sealed package (Maga, 1979). Besides, it appeared in foods such as meat, nuts, coffee and other beverages including beer (FDA, 2004; Zoller et al., 2007; Morehouse et al., 2008; Fromberg et al., 2014; EFSA, 2017).

In beer, the furan content ranged from 5 to $13 \mu \mathrm{g} / \mathrm{L}$ (FDA, 2004). According to a European Food Safety Authority study carried out on 102 beer samples, furan was detected at 3.0-5.2 $\mu \mathrm{g} / \mathrm{L}$ (EFSA, 2011). Beer analyzed in Taiwan showed the furan range from 3.0 to $20.0 \mu \mathrm{g} / \mathrm{L}$ (Liu and Tsai, 2010). The highest furan concentration of 13 analyzed beer samples in China was $15.2 \mu \mathrm{g} / \mathrm{L}$ (Sijia et al., 2014).

The first quantitative method for the determination of furan in food was published by FDA (FDA, 2004). Due to the high volatility of furan, the samples are cooled to
$+4{ }^{\circ} \mathrm{C}$ before handling. A headspace technique is used for the determination of furan where the sample is incubated at $80^{\circ} \mathrm{C}$. A PLOT (porous layer open tubular) column is used for the chromatographic separation. This type of column with a bound polystyrene-divinylbenzene phase can effectively separate small volatile molecules. Quantification is based on a standard addition method using deuterated furan (d4-furan) as an internal standard.

The headspace technique is based on the principle that heating of a sample releases volatile substances into the steam space. For furan, excessive heating of the sample is inappropriate and unnecessary. Becalski, Forsyth et al. (2005) showed that increasing the incubation temperature from $30{ }^{\circ} \mathrm{C}$ to $50{ }^{\circ} \mathrm{C}$ results in only a $50 \%$ increase in the furan peak area. By adding salt, the furan signal is more than doubled. Because of the risk of furan formation from its precursors, the incubation temperature of the sample at $50{ }^{\circ} \mathrm{C}$ or lower is usually used.

Some authors used the SPME (solid phase microextraction) technique instead of the classical headspace method (Cerny and Davidek, 2003; Goldmann et al., 2005; Ho et al., 2005; Bianchi et al., 2006; Condurso 
et al., 2018). In contrast to the headspace technique, where a portion of the vapor phase of the sample is directly loaded on the chromatography column, in the SPME procedure a polymer coated needle is exposed in the vapor space where volatile substances are absorbed for 10 to $60 \mathrm{~min}$. Then, the SPME fiber is introduced into a gas chromatograph injector where the analytes are thermally desorbed for 1 to $5 \mathrm{~min}$ at 90 to $300{ }^{\circ} \mathrm{C}$. This procedure allows higher concentration of analytes and hence, better sensitivity. The detection limit is therefore very low, namely ng/kg (Goldmann et al., 2005; Bianchi et al., 2006).

The chromatographic separation of furan from other volatile substances often takes place on PLOT columns and the temperature program starts between 20 and $50{ }^{\circ} \mathrm{C}$ (Cerny and Davidek, 2003; Reinhard et al., 2004; Becalski and Seaman, 2005; Goldmann et al., 2005; Ho et al., 2005; Senyuva and Gökmen, 2005; Bianchi et al., 2006; Hasnip et al., 2006).

Gas chromatography with a mass detector is also used for the identification and quantification of furan (Becalski et al., 2016). In this case, apart from the identification of furan using the retention time match (deviation from the standard $\pm 2 \%$ ), the verification of the ratio of the furan molecular ion at $\mathrm{m} / \mathrm{z} 68$ to its ion fragment at $\mathrm{m} / \mathrm{z} 39$ in comparison with the standard (deviation $\pm 10 \%$ ) is also used. A deuterated internal standard is used for the quantification. The recoveries are around $90 \%$ and the limit of detection is about $1 \mu \mathrm{g} / \mathrm{kg}$. The published results show that the headspace method in combination with gas chromatography and mass detection provides excellent results (Crew and Castle, 2007).

The aim of this work was to elaborate and optimize a simple and robust method for the determination of furan in beer using the headspace method and capillary gas chromatography with the flame ionization detector.

\section{Materials and methods}

Furan (> 99\%, Supelco, CZ) was used as the standard. Ethyl methyl sulfide at $96 \%$ purity (internal standard) was purchased from Aldrich. Ammonium sulfate in p. a. quality was purchased from Lach-Ner (CZ).

The DB-WAX capillary column with the length of $60 \mathrm{~m}$, inner diameter of $0.32 \mathrm{~mm}$ and the film thickness of $0.25 \mu \mathrm{m}$ was supplied by Agilent (CA, USA).

Gases in cylinders - helium in quality 5.0, hydrogen in quality 5.0, synthetic air and nitrogen in quality 4.6 supplied by Air Products (CZ).

The samples of pilsner beer produced in the Czech Republic were bought in a local store.
The determination was performed on an Agilent Technologies 7890B gas chromatograph equipped with a split/splitless injector and flame-ionization detector (Agilent, CA, USA). The gas chromatograph was equipped with a PAL RSI 85 automatic headspace sampler and a Clarity data station.

The chromatographic column was heated to the initial temperature of $47^{\circ} \mathrm{C}$, which was maintained for $0.7 \mathrm{~min}$ after the sample injection. A temperature gradient of $30{ }^{\circ} \mathrm{C} / \mathrm{min}$ to $200{ }^{\circ} \mathrm{C}$ then followed and this constant temperature was maintained for $6 \mathrm{~min}$. The sample $(600 \mu \mathrm{l})$ was injected in the split mode with a split ratio of $1: 10$. Both injector and detector temperatures were equal, namely $220^{\circ} \mathrm{C}$. Helium 5.0 was used as the carrier gas and the head pressure was set to $200 \mathrm{kPa}$ at $120^{\circ} \mathrm{C}$.

An internal standard method was used for the quantification, using ethyl methyl sulfide as the internal standard.

\section{Results and discussion}

The dependence of the furan signal response on the incubation temperature of the sample was tested during the optimization. Ten milliliters of the sample in a $20 \mathrm{~mL}$ headspace vial was shaken at $250 \mathrm{rpm}$ for $13 \mathrm{~min}$ in the incubator of the headspace sampler. The incubation time was chosen according to the length of chromatographic analysis, including the system conditioning. The addition of $4 \mathrm{~g}$ ammonium sulfate was used to promote the transfer of furan to the vapor space. The results are shown in Table 1. An increase in the incubation temperature from $30{ }^{\circ} \mathrm{C}$ to $70{ }^{\circ} \mathrm{C}$ results in an only about $50 \%$ increase in the furan response. To prevent a possible increase in the furan content by its formation from precursors (Crew and Castle, 2007), the temperature of $50{ }^{\circ} \mathrm{C}$ was chosen for further experiments

Table 1 Dependence of furan signal response on incubation temperature

Incubation temperature $\left({ }^{\circ} \mathrm{C}\right) \quad$ Relative response of furan $(\%)$

\begin{tabular}{|c|c|}
\hline 30 & 100 \\
\hline 50 & 126 \\
\hline 70 & 148 \\
\hline
\end{tabular}

Linearity, recovery and repeatability of the method were verified within the method validation. For this purpose, standard solutions of the analytes of interest were prepared in a $5 \%(\mathrm{v} / \mathrm{v})$ ethanol solution.

The calibration curve was measured over a concentration range from 0.936 to $18.72 \mu \mathrm{g} / \mathrm{L}$. The correlation coefficient showed a value of 0.999 using linear regres- 
sion. The method is thus characterized by high linearity within a given concentration range.

The accuracy of the method was verified by recovery. First, the furan content of five real beer samples was measured. Then, the same beer samples were enriched by the addition of furan at the concentration levels of $4.7 \mu \mathrm{g} / \mathrm{L}$ and $18.7 \mu \mathrm{g} / \mathrm{L}$. Furan recovery at $4.7 \mu \mathrm{g} / \mathrm{L}$ and $18.7 \mu \mathrm{g} / \mathrm{L}$ reached $85 \%$ and $91 \%$, respectively.

The repeatability of the method was determined by repeating the whole procedure five times within one day on one beer sample, which was enriched by furan at two concentration levels $-2.7 \mu \mathrm{g} / \mathrm{L}$ and $12.8 \mu \mathrm{g} / \mathrm{L}$. The relative standard deviations (RSD) were $7.2 \%$ and $5.5 \%$, respectively. Since the enrichment of a beer sample with furan alone contributes to the deterioration in the repeatability value, the RSD results can be considered as fully acceptable.

The limit of detection was determined as a threefold of a standard deviation of the blank, and it showed a value of $0.05 \mu \mathrm{g} / \mathrm{L}$. The limit of determination was determined as a tenfold of a standard deviation of the blank noise and is $0.18 \mu \mathrm{g} / \mathrm{L}$.

Figure 1 shows the chromatogram of a real beer sample. It shows good interference-free furan separation.

Attention was also paid to the repeatability of retention times. For this purpose, the same sample was measured thirteen times. Table 2 shows relative standard deviations of retention times for furan and ethyl methyl sulfide. The results show that the reproducibility, expressed as relative standard deviation of retention times, is better than $0.12 \%$.

\section{Conclusion}

This study shows that the headspace/gas chromatographic method for furan determination in beer using ethyl methyl sulfide as an internal standard represents a reliable and fast procedure suitable for routine analysis. The application of ethyl methyl sulfide as an internal standard allows the use of an inexpensive, conventional flame ionization detector.

\section{Acknowledgement}

This study was supported by the project MZE-R01918 "Research of the quality and processing of malting and brewing raw materials" of the Ministry of Agriculture of the Czech Republic.

\section{References}

Becalski, A., Forsyth, D., Casey, V., Lau, B. P.-Y., Pepper, K., Seaman, S., 2005 : Development and validation of a headspace method for determination of furan in food. Food Addit. Contam., 22(6): 535-540. https:// doi.org/10.1080/02652030500129170

Becalski, A., Halldorson, T., Hayward, S., Roscoe, V., 2016: Furan, 2-methylfuran and 3-methylfuran in coffee on the Canadian market. J. Food Compos. Anal., 47: 113-119. https://doi.org/10.1016/j. jfca.2016.01.006

Becalski, A., Seaman, S., 2005: Furan precursors in food: a model study and development of a simple headspace method for determination of furan. J. AOAC Int., 88(1): 102-106.

Figure 1 The chromatogram of a real beer sample

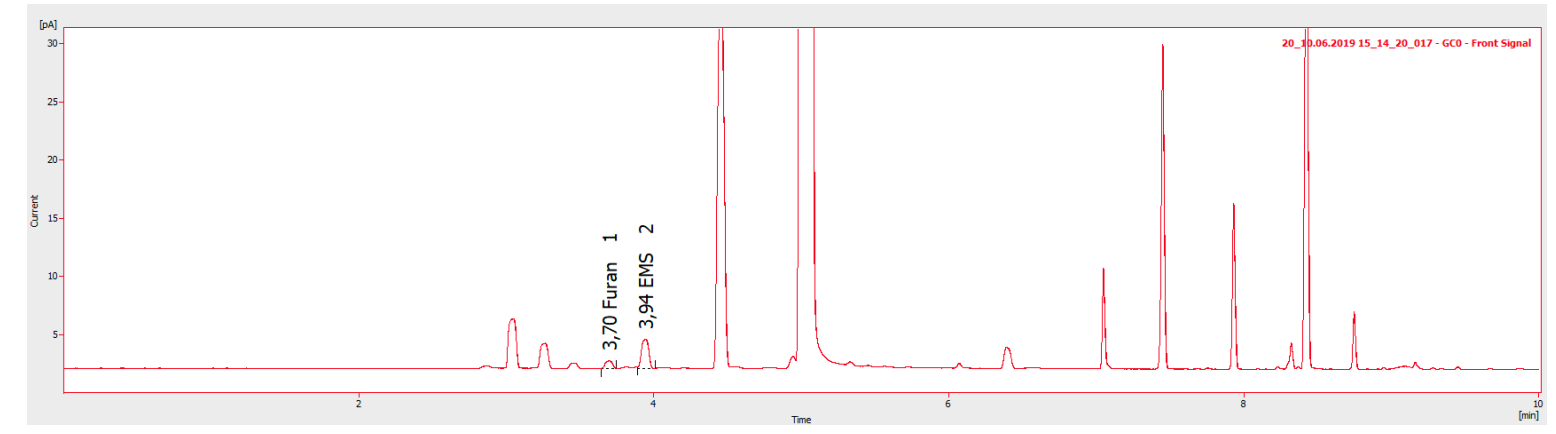

Table 2 Relative standard deviation of retention times (RSD tr) of furan and ethyl methyl sulfide measured on column DB WAX $60 \mathrm{~m}, 0.32 \mathrm{~mm}$ I.D., $0.25 \mu \mathrm{m}$.

\begin{tabular}{|c|c|}
\hline Compound & RSD tr (\%) \\
\hline Furan & 0.11 \\
\hline Ethyl methyl sulfide & 0.11 \\
\hline
\end{tabular}

Furan was determined by this method in 55 samples of pilsner lagers. The determined content ranged from 0.2 to $5.1 \mu \mathrm{g} / \mathrm{L}$.
Bianchi, F., Careri, M., Mangia, A., Musci, M., 2006: Development and validation of a solid phase micro-extraction-gas chromatography-mass spectrometry method for the determination of furan in baby-food. J. Chromatogr. A, 1102(1-2): 268-272. https://doi.org/10.1016/j. chroma.2005.10.056

Condurso, C., Cincotta, F., Verzera, A., 2018: Determination of furan and furan derivates in baby food. Food Chem., 250: 155-161. https://doi. org/10.1016/j.foodchem.2017.12.091

Cerny, C., Davidek, T., 2003: Formation of aroma compounds from ribose and cysteine during the Maillard reaction. J. Agric. Food Chem., 51(9): 2714-2721. https://doi.org/10.1021/jf026123f 
Crews, C., Castle, L., 2007: A review of the occurrence, formation and analysis of furan in heat-processed foods. Trends Food Sci. Technol., 18(7): 365-372. https://doi.org/10.1016/j.tifs.2007.03.006

EFSA (European Food Safety Authority), 2011: Update on furan levels in food from monitorings years 2004-2010 and exposure assessment. EFSA J., 9(9): 2347. https://doi.org/10.2903/j.efsa.2011.2347

EFSA (European Food Safety Authority), 2017: Risk for public health related to the presence of furan and methylfurans in food. EFSA J., 15(10): 5005. https://doi.org/10.2903/j.efsa.2017.5005

FDA, 2004. Exploratory data on furan in food. Data through May 27, 2004. Available at https://www.fda.gov/food/chemicals/exploratory-data-furan-food.

Fromberg, A., Mariotti, M. S., Pedreschi, F., Fagt, S., Granby, K., 2014: Furan and alkylated furans in heat processed food, including home cooked products. Czech J. Food Sci., 32(5): 443-448. https://doi. org/10.17221/341/2013-CJFS

Goldmann, T., Périsset, A., Scanlan, F., Stadler, R. H., 2005: Rapid determination of furan in heated foodstuffs by isotope dilution solid phase micro-extraction-gas chromatography-mass spectrometry (SPMEGC-MS). Analyst, 130(6): 878-883.

Hasnip, S., Crews, C., Castle, L., 2006: Some factors affecting the formation of furan in heated foods. Food Addit. Contam., 23(3): 219-227. https://doi.org/10.1080/02652030500539766

Ho, I.-P., Yoo, S.-J., Tefera, S., 2005: Determination of furan levels in coffee using automated solid-phase microextraction and gas chromatography/mass spectrometry. J. AOAC Int., 88(2): 574-576.

International Agency for Research on Cancer, 1995: Dry cleaning, some chlorinated solvents and other industrial chemicals. In: IARC monographs on the evaluation of carcinogenic risks to humans, pp. 394407, Vol. 63. Lyon: IARC
Liu, Y.-T., Tsai, S.-W., 2010: Assessment of dietary furan exposures from heat processed foods in Taiwan. Chemosphere, 79(1): 54-59. https://doi.org/10.1016/j.chemosphere.2010.01.014

Maga, J. A., Katz, I., 1979: Furans in foods. CRC Crit. Rev. Food Sci. Nutr., 11(4): 355-400. https://doi.org/10.1080/10408397909527268

Morehouse, K. M., Nyman, P. J., McNeal, T. P., DiNovi, M. J., Perfetti, G. A., 2008: Survey of furan in heat processed foods by headspace gas chromatography/mass spectrometry and estimated adult exposure. Food Addit. Contam., 25(3), 259-264. https://doi. org/10.1080/02652030701552949

Reinhard, H., Sager, F., Zimmermann, H., Zoller, O., 2004: Furan in foods on the Swiss market - method and results. Mitt. Lebensmittelunters. Hyg., 95(5): 532-535.

Senyuva, H. Z., Gökmen, V., 2005: Analysis of furan in foods. Is headspace sampling a fit-for-purpose technique? Food Addit. Contam., 22(12): 1198-1202. https://doi.org/10.1080/02652030500337310

Sijia, W., Enting, W., Yuan, Y., 2014: Detection of furan levels in select Chinese foods by solid phase microextraction-gas chromatography/ mass spectrometry method and dietary exposure estimation of furan in the Chinese population. Food Chem. Toxicol., 64, 34-40. https:// doi.org/10.1016/j.fct.2013.11.012

Zoller, O., Sager, F., Renhard, H., 2007: Furan in foods: Headspace method and product survey. Food Addit. Contam., 24, 91-107. https://doi. org/10.1080/02652030701447389 